\title{
Signal Enhancement of Indirect-Competitive Metallothionein Immunosensor by Horseradish-Peroxidase-Induced Precipitation of Diaminobenzidine Derivatives
}

\author{
Namsoo Kim* \\ Research Group of Convergence Technology, Korea Food Research Institute, \\ Seongnam 463-746, Republic of Korea
}

(Received February 17, 2014; accepted September 12, 2014)

Key words: signal enhancement, indirect-competitive metallothionein sensor, horseradish peroxidase (HRP)-induced precipitation, diaminobenzidine derivatives

An indirect-competitive quartz crystal microbalance immunosensor is well acknowledged as a tool for biological detection. As a method of improving sensitivity, horseradish-peroxidase-induced precipitation of 3,3'-diaminobenzidine (DAB) derivatives to the sensor surface, which was confirmed by field emission-scanning electron microscopy imaging, was conducted using metallothionein (MT) as a model analyte. The sensor signal was enhanced up to 5.3-fold when the DAB concentration was varied from 0.1 to $2 \mathrm{mM}$ at the secondary antibody concentration of $10 \mu \mathrm{g} / \mathrm{ml}$. Linearity in response signal was found in the MT range of $0.05-1 \mathrm{ng} / \mathrm{ml}$, with the limit of detection of $50 \mathrm{pg} / \mathrm{ml}$. The present biosensor can serve as a highly sensitive detection tool for biomarkers of physiological importance.

\section{Introduction}

Possible contamination with xenobiotics such as mercury and cadmium in living organisms including humans is of critical concern with respect to eco-toxicological and nutritional viewpoints. ${ }^{(1-3)}$ Metallothionein (MT) is a cysteine-rich metal-binding protein and a potent biomarker protein that is specifically produced up to several hundred $\mu \mathrm{g} / \mathrm{g}$ body weight in response to extraneously introduced heavy metals. Thus, MT is a useful monitoring target, as a sum parameter, for detecting contamination with heavy metals in living organisms, ${ }^{(2,4-6)}$ and MT measurement has been an important issue in bioanalytical chemistry. ${ }^{(7-9)}$

*Corresponding author: e-mail: k9130sen@hanmail.net 
The quartz crystal microbalance (QCM) technique that uses a mass-sensitive detector based on an oscillating piezoelectric (PZ) crystal has been widely used in affinity-based biosensing. It has some advantages including high-sensitivity, real-time presentation of signals, cost-effectiveness, and simple operation. ${ }^{(10-13)}$ Label-free QCM immunosensing based on the indirect-competitive (IC) assay format has been found efficient and competitive for biological detection. ${ }^{(10,11,14,15)}$ Moreover, the sensitivity of a QCM immunosensor was expected to be amplified significantly by increasing the mass deposition rate via the precipitation of insoluble products produced by the reaction of labeled enzymes such as horseradish peroxidase (HRP) with chromogenic substrates comprising 4-chloro-1-naphthol $(\mathrm{CN})$ and 3,3'-diaminobenzidine (DAB). ${ }^{(16-18)}$ The aim of this study is to develop an IC MT sensor that is operated by signal enhancement owing to the HRP-induced precipitation of $\mathrm{DAB}$ derivatives on the sensor surface.

\section{Materials and Methods}

\subsection{Reagents and transducer}

A rabbit MT (96\% pure) was obtained from Ikzus Ricerche Mare e Ambiente (Genova, Italy). A protein G-purified monoclonal anti-rabbit MT antibody (1 mg/ $\mathrm{ml}$ ) produced in mouse and an HRP-labeled goat anti-mouse IgG (HRP-G-AntiMSIgG) were purchased from TransGenic (Kobe, Japan) and Abcam (Cambridge, UK), respectively. CN and DAB were purchased from Sigma-Aldrich (St. Louis, MO, USA), and a heterobifunctional thiolation cross-linker, sulfosuccinimidyl 6-[3-(2-pyridyldithio) propionamido]hexanoate (sulfo-LC-SPDP), was obtained from Pierce (Rockford, IL, USA). All other chemicals were guaranteed reagents from various suppliers, and doubledistilled water was used throughout this study. For use as transducer, an AT-cut $9 \mathrm{MHz}$ PZ quartz wafer (QA 9RP-50), attached with two gold electrodes of $5 \mathrm{~mm}$ diameter, was obtained from Seiko EG \& G (Matsudo, Japan).

\subsection{Immobilization of coating antigen}

The coating antigen in this study (MT itself) was separately immobilized on the transducer surface by $N$-(3-dimethylaminopropyl)- $N$ '-ethylcarbodiimide (EDC)- $N$ hydroxysulfosuccinimide (NHS) ${ }^{(11)}$ and sulfo-LC-SPDP coupling. ${ }^{(13)}$ In both cases, the concentration of the coating antigen for immobilization was $1 \mathrm{mg} / \mathrm{ml}$, and surface blocking with $1 \%$ BSA was conducted after immobilization to avoid nonspecific adsorption during the following measurements.

\subsection{System construction and operation}

The sensor system was constructed on the basis of a previous report. ${ }^{(19)}$ The MT sensor was optimized for conditions of signal enhancement as follows. Initially, the QCM chip immobilized with $1 \mathrm{mg} / \mathrm{ml}$ MT was fixed on the bottom of the well cell (QA-CL4) of Seiko EG \& G. To $270 \mu \mathrm{l}$ of $0.1 \mathrm{M}$ sodium potassium phosphate buffer (pH 7.0), i.e., the reaction buffer, added to the well cell, $30 \mu \mathrm{l}$ of $50 \mu \mathrm{g} / \mathrm{ml}$ anti-MT antibody was added. After the immune reaction with the immobilized coating antigen for $30 \mathrm{~min}$, the reaction mixture was withdrawn from the reaction cell, followed by rinsing twice, first, with the reaction buffer, and then with distilled water. Afterward, $270 \mu 1$ of the reaction 
buffer and $30 \mu \mathrm{l}$ each of the diluted HRP-G-Anti-MSIgG $(10,20$, and $100 \mu \mathrm{g} / \mathrm{ml})$ were added to the reaction cell, and complexation between the bound primary antibody and the secondary antibody lasted for $30 \mathrm{~min}$. After removing the secondary antibody solution, the QCM surface was rinsed as described above. Finally, $270 \mu \mathrm{l}$ of the reaction buffer was added to the reaction cell, and the resonant frequency from the quartz crystal analyzer was recorded until a stable baseline frequency $\left(F_{0}\right)$ was obtained. At this point, $30 \mu \mathrm{l}$ of the substrate solution that included $10 \mathrm{mM} \mathrm{CN}$ and $4.078 \mathrm{mM} \mathrm{H}_{2} \mathrm{O}_{2}$ or varying concentrations of $\mathrm{DAB}$ and $10 \mathrm{mM} \mathrm{H}_{2} \mathrm{O}_{2}$ was added to initiate the $\mathrm{HRP}$-induced precipitation of substrate derivatives. With the progress of the precipitation, the timedependent resonant frequency $\left(F_{t}\right)$ gradually decreased. ${ }^{(20)}$ The frequency shift at time $t$ $\left(\Delta F=F_{0}-F_{t}\right)$ was then calculated. The sensor signal eventually converged to another stable resonant frequency, and the frequency shift at this point was regarded as a sensor response. The sensor surface was regenerated before the next use by treating it with 300 $\mu \mathrm{l}$ of $10 \mathrm{mM} \mathrm{NaOH}$ for approximately $10 \mathrm{~s}$, followed by rinsing with the reaction buffer three times. For analyte measurement, the IC immune reaction between the immobilized coating antigen and free analytes in the range of $0.05-10 \mathrm{ng} / \mathrm{ml}$ for the primary antibody was conducted using the above procedure.

\subsection{Analytical pathway of IC MT immunosensor based on signal enhancement owing to HRP-induced precipitation of substrate derivatives}

The pathway of IC binding of the primary antibody, binding of the secondary antibody, and signal enhancement by HRP-induced precipitation of substrate derivatives is schematically shown with $\mathrm{DAB}$ as the precipitating substrate (Fig. 1). When a mixture
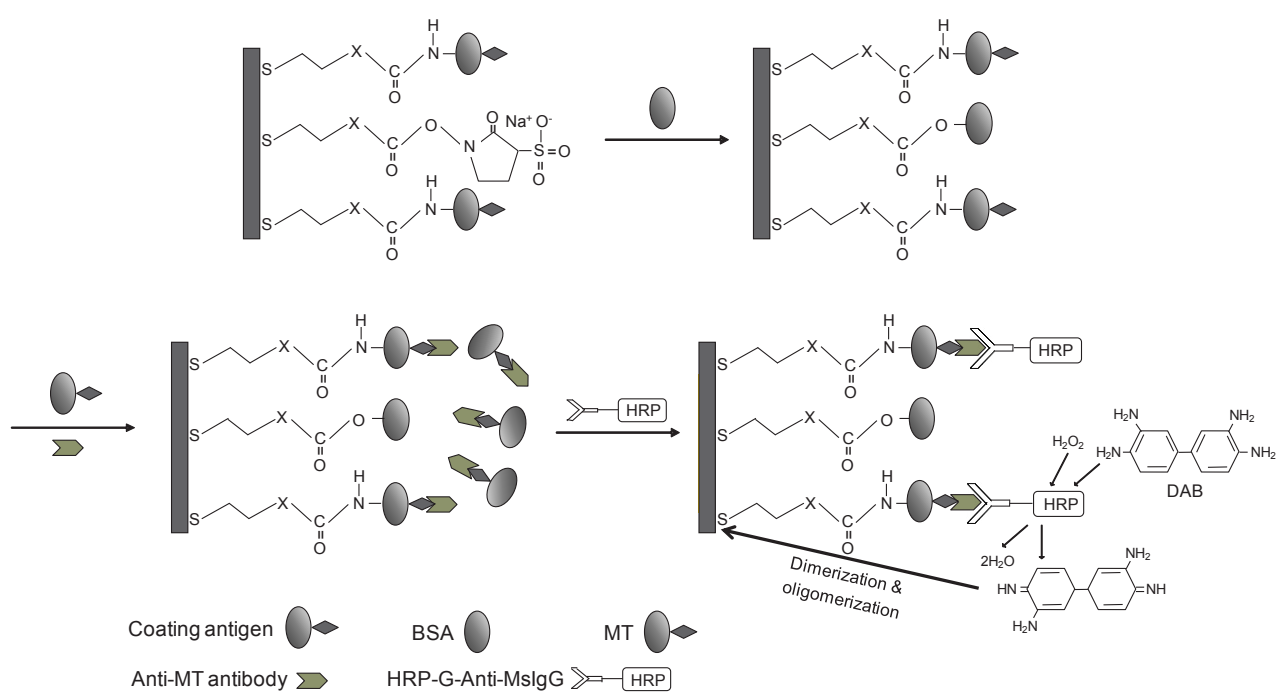

Fig. 1. (Color online) Schematic representation of HRP-induced precipitation of DAB derivatives leading to signal enhancement of IC MT sensor that exploits QCM transducer. 
that includes the primary antibody and the analyte is added to the reaction cell, the IC immune reaction takes place. After the secondary antibody is bound to the primary antibody on the sensor surface, DAB in the substrate mixture is converted to condensed derivatives that are less soluble in the buffer solution, via 4,4'-diimino-3,3'-diaminobiphenyl, and then precipitated to the QCM surface, which results in increased mass deposition rate accompanied by an enhanced sensor signal.

\subsection{Field emission-scanning electron microscopy (FE-SEM) imaging of sensor surface}

The QCM surface before and after the reaction with DAB substrate was scanned with an FE-SEM (model S-4700, Hitachi, Tokyo, Japan) at an acceleration voltage of $10 \mathrm{kV}$. Depending on the sample, the working distance between the lens and the specimen was adjusted to the range of $6.5-6.8 \mathrm{~mm}$. The magnification used was $50000-$ or 100000 -fold, and the secondary electron signal obtained from the upper sample surface was imaged with the instrument.

\section{Results and Discussion}

\subsection{Optimization of precipitating substrate and substrate concentration}

When measured using $1 \mathrm{mM} \mathrm{CN}$ as the precipitating substrate at the concentrations of the secondary antibody of 1,2 , and $10 \mu \mathrm{g} / \mathrm{ml}$, and the concentration of the primary antibody of $5 \mu \mathrm{g} / \mathrm{ml}$ in the well cell, the sensor responses of $4.0-14.7$ and $1.4-14.9 \mathrm{~Hz}$ were acquired for EDC-NHS and sulfo-LC-SPDP coupling, respectively. Compared with the sensor signal of $185.4 \mathrm{~Hz}$ obtained with complexation between the coating antigen and primary antibody without HRP-induced precipitation, these values were very weak. This fact indicated that $\mathrm{CN}$ was inefficient as the precipitating substrate for MT sensing.

Thus, another precipitating substrate was tested. DAB that is oxidized in the presence of HRP may undergo further catalytic oxidation, which forms dimers and oligomers including tetramers, with a resultant reduced water solubility leading to precipitation. ${ }^{(12)}$ Sensor responses at varying concentrations of the secondary antibody of 1,2 , and $10 \mu \mathrm{g} /$ $\mathrm{ml}$ were determined using $0.34 \mathrm{mM}$ DAB. As shown in Table 1, sensor signals were clearly enhanced with regard to the concentration of the secondary antibody.

Table 1

Sensor responses obtained with DAB substrate in relation to secondary antibody concentration. The sensor response caused by the addition of the reaction buffer instead of the substrate solution was negligible.

\begin{tabular}{cc}
\hline Secondary antibody $(\mu \mathrm{g} / \mathrm{ml})^{\mathrm{a}}$ & Sensor response $(\mathrm{Hz})^{\mathrm{b}}$ \\
\hline 1 & $144.0 \pm 17.2^{\mathrm{c}}$ \\
2 & $171.0 \pm 12.6$ \\
10 & $407.0 \pm 14.8$ \\
\hline
\end{tabular}

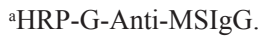

${ }^{\text {b} M e a s u r e d ~ w i t h ~ Q C M ~ c h i p ~ i m m o b i l i z e d ~ w i t h ~} 1 \mathrm{mg} / \mathrm{ml}$ MT by sulfo-LC-SPDP coupling, and the substrate solution containing 0.34 and $1 \mathrm{mM}$ of DAB and $\mathrm{H}_{2} \mathrm{O}_{2}$, respectively.

cMean $\pm \operatorname{SD}(n=7)$. 
The effect of DAB concentration on the sensor signal was evaluated at $0.1-2 \mathrm{mM}$ DAB (Fig. 2). In this case, the concentration of the secondary antibody was fixed at 10 $\mu \mathrm{g} / \mathrm{ml}$. In most cases, the sensor responses obtained increased with the increase in DAB concentration, and the maximal sensor signal of $982.3 \mathrm{~Hz}$ was obtained at $2 \mathrm{mM}$ DAB. Compared with $185.4 \mathrm{~Hz}$ obtained with the sensor without undergoing precipitation, the degree of signal enhancement was approximately 5.3-fold.

The surface of the QCM sensor was observed by FE-SEM imaging before and after the HRP reaction. The 2D FE-SEM image of the gold electrode of the untreated QCM [Fig. 3(a)] showed a smooth and grained surface consisting of an ovular repeating structure of approximately $50 \mathrm{~nm}$ diameter, as reported previously with atomic force microscopy. ${ }^{(21)} \mathrm{In}$ contrast, the QCM showed a quite different surface structure after the formation of the immune complex between the primary and secondary antibodies [Fig. 3(b)]. That is, blackish amorphous regions that seemed to indicate the immune complex were found throughout the surface. After the HRP reaction with DAB substrate, however, a more significant and fundamental change occurred on the QCM surface. The characteristic ovular repeating structure of the gold electrode was no longer distinct although the immune complex between the primary and secondary antibodies remained everywhere at high magnification [Fig. 3(c)] and low magnification [Fig. 3(d)]. White precipitates were also found in different places. The HRP-induced precipitation of DAB derivatives to the QCM surface seemed to bring about these changes.

\subsection{Analyte measurement using signal-enhanced IC MT sensor}

Responses of the IC MT sensor were measured with the sensor chips prepared by sulfo-LC-SPDP coupling at varying MT concentrations of $0.005-1 \mathrm{ng} / \mathrm{ml}$ using $2 \mathrm{mM}$

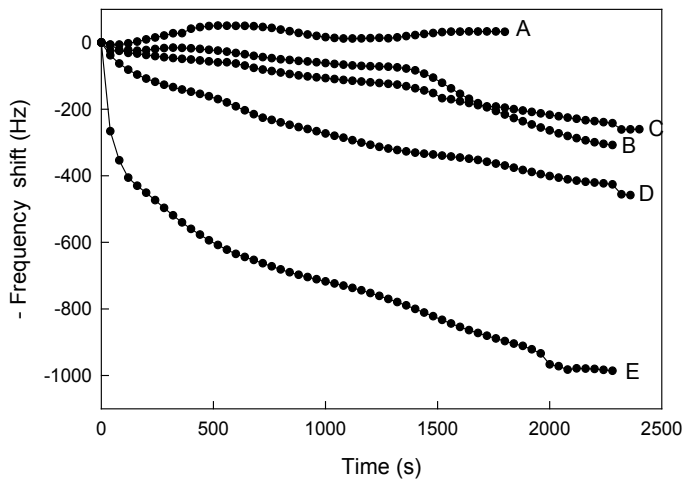

(a)

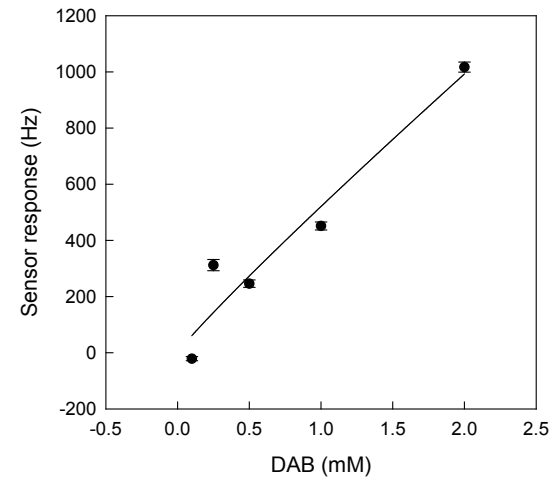

(b)

Fig. 2. (a) Time-dependent frequency shifts of QCM sensor immobilized with $1 \mathrm{mg} / \mathrm{ml}$ MT by sulfo-LC-SPDP coupling at varying concentrations of DAB substrate and (b) relationship between $\mathrm{DAB}$ concentration and sensor response. DAB concentrations $(\mathrm{mM}): \mathrm{A}, 0.1 ; \mathrm{B}, 0.25 ; \mathrm{C}, 0.5 ; \mathrm{D}, 1 ; \mathrm{E}, 2$. The concentration of the cosubstrate $\left(\mathrm{H}_{2} \mathrm{O}_{2}\right)$ was adjusted to $1 \mathrm{mM}$. In (b), seven values of sensor response at adjacent measurement time were averaged and error bars were inserted. 


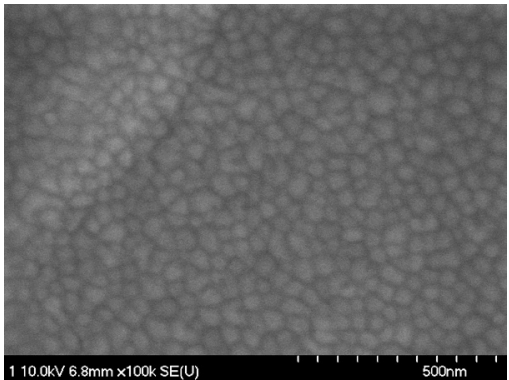

(a)

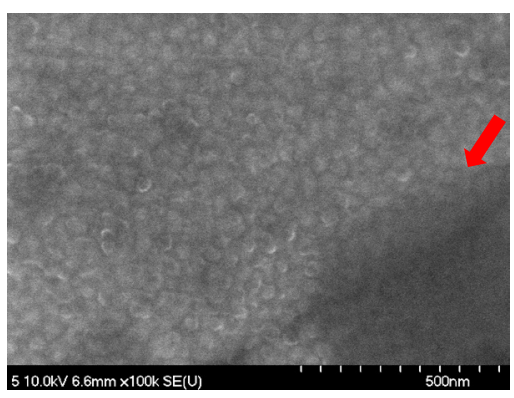

(c)

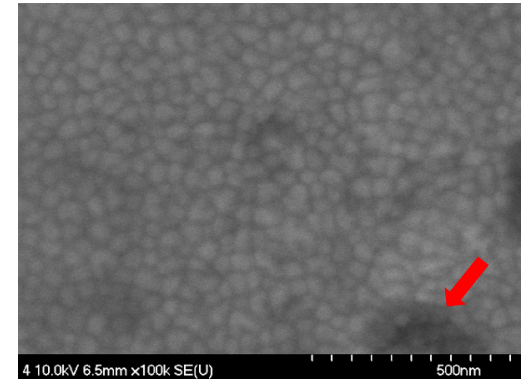

(b)

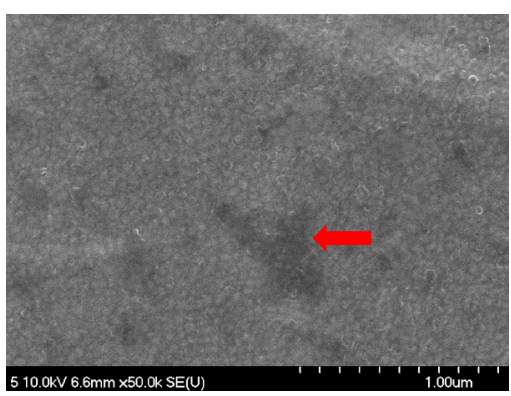

(d)

Fig. 3. (Color online) FE-SEM images of QCM surface according to progression of the enzymatic reaction: (a) untreated QCM measured at $\times 100 \mathrm{k}$; (b) after formation of the immune complex between the primary and secondary antibodies measured at $\times 100 \mathrm{k}$; (c) after the enzymatic reaction with $\mathrm{DAB}$ substrate measured at $\times 100 \mathrm{k}$; (d) after the enzymatic reaction with DAB substrate measured at $\times 50 \mathrm{k}$. The blackish amorphous regions indicated by arrows show the immune complex between the primary and secondary antibodies.

$\mathrm{DAB}$ as the precipitating substrate. Resonant frequencies of the sensor decreased abruptly after the addition of the substrate mixture at all analyte concentrations, followed by stabilization in the baseline frequency mostly within $30 \mathrm{~min}$. As shown in Fig. 4(a), sensor responses were inversely related with MT concentration, and the sensor response at $50 \mathrm{pg} / \mathrm{ml} \mathrm{MT}$ was lower than the control response of $1079.4 \mathrm{~Hz}$ by $204.0 \mathrm{~Hz}$. From this fact and a normally accepted criterion that a response more than threefold of the standard deviation for the baseline drift is regarded as a meaningful sensor signal, the limit of detection (LOD) of the present sensor was estimated at $50 \mathrm{pg} / \mathrm{ml}$. The sensitivity obtained was better than those of previous MT measurements including enzyme-linked immunosorbent assay (ELISA). ${ }^{(19,22-24)}$ When plotted in double-logarithmic scales, ${ }^{(25)}$ linearity in sensor response was attained at the MT concentrations of $0.05-1 \mathrm{ng} / \mathrm{ml}$, with the regression equation of $Y\left(\log _{10}\right.$ sensor response $)=-0.2310 X\left(\log _{10} M T\right)+2.6516(r$ $=0.9834$ ) $[$ Fig. 4(b)]. As can be seen from a high correlation coefficient of 0.9838 , the convergence of the sensor responses at varying MT concentrations was found to be good. 


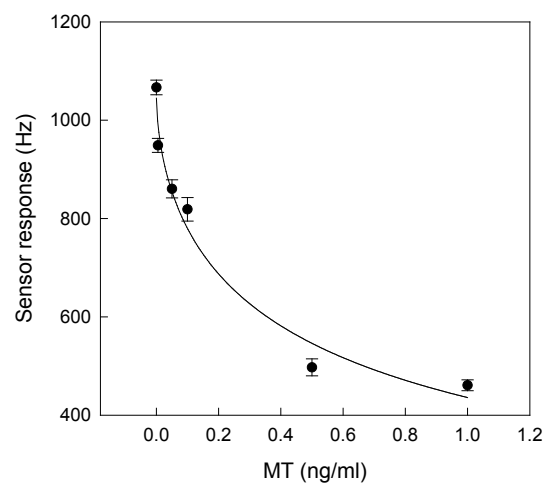

(a)

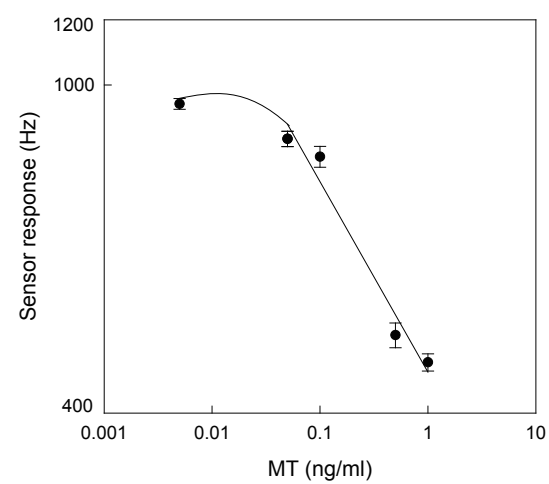

(b)

Fig. 4. Sensor response as a function of analyte concentration plotted in (a) normal and (b) double-logarithmic scales. Seven values of sensor response at adjacent measurement time were averaged and error bars were inserted.

\section{Conclusions}

A clear enhancement in the response signal of an IC MT sensor, up to 5.3-fold, was obtained following HRP-induced precipitation of DAB derivatives at the optimized operating conditions of signal enhancement. By using the sensor, an LOD of $50 \mathrm{pg} /$ $\mathrm{ml}$ was obtainable in an aqueous buffer system. The signal enhancement principle established here might find applicability to qualitative and quantitative immunological detections of low-molecular-weight hazardous substances comprising pesticides and endocrine disruptors, and biomarker proteins of physiological importance such as vitellogenin in the biosphere, agricultural and fisheries produce, and food products.

\section{Acknowledgements}

This work was supported by the Korea Food Research Institute, Republic of Korea, under the research project "High Sensitivity Detection of Heavy Metal Biomarker for Food Safety Securement".

\section{References}

1 J. S. Garvey: Environ. Health Perspect. 54 (1984) 117.

2 J. Petrlova, S. Krizkova, O. Zitka, J. Hubalek, R. Prusa, V. Adam, J. Wang, M. Beklova, B. Sures and R. Kizek: Sens. Actuators, B 127 (2007) 112.

3 W. Tang, T. Kido, W. A. Gross, K. Nogawa, E. Sabbioni and Z. A. Shaikh: J. Anal. Toxicol. 23 (1999) 153.

4 H. M. Chan, G. A. Pringle and M. G. Cherian: J. Biochem. Toxicol. 7 (1992) 219. 
5 A. Viarengo, E. Ponzano, F. Dondero and R. Fabbri: Mar. Environ. Res. 44 (1997) 69.

6 A. Yasutake and M. Nakamura: J. Toxicol. Sci. 36 (2011) 365.

7 J. Jebali, M. Banni, H. Gerbej, H. Boussetta, J. López-Barea and J. Alhama: Mar. Environ. Res. 65 (2008) 358.

8 M. Lacorn, A. Lahssen, N. Rotzoll, T. J. Simat and H. Steinhart: Environ. Toxicol. Chem. 20 (2001) 140 .

9 T. Minami, S. Ichida and K. Kubo: J. Chromatogr. B 781 (2002) 303.

10 S. Babacan, P. Pivarnik, S. Letcher and A. G. Rand: Biosens. Bioelectron. 15 (2000) 615.

11 X. Jin, X. Jin, X. Liu, L. Chen, J. Jiang, G. Shen and R. Yu: Anal. Chim. Acta 645 (2009) 92.

12 S. P. Martin, J. M. Lynch and S. M. Reddy: Biosens. Bioelectron. 17 (2002) 735.

13 I.-S. Park and N. Kim: Biosens. Bioelectron. 13 (1998) 1091.

14 J. Halámek, A. Makower, P. Skládal and F. W. Scheller: Biosens. Bioelectron. 17 (2002) 1045.

15 N. Kim, D.-K. Kim and Y.-J. Cho: Sens. Actuators, B 143 (2009) 444.

16 J. M. Abad, F. Pariente, L. Hernández, H. D. Abruña and E. Lorenzo: Anal. Chem. 70 (1998) 2848 .

17 L. Alfonta, A. K. Singh and I. Willner: Anal. Chem. 73 (2001) 91.

18 S. M. Reddy, J. P. Jones, T. J. Lewis and P. M. Vadgama: Anal. Chim. Acta 363 (1998) 203.

19 D. G. Thomas, H. J. Linton and J. S. Garvey: J. Immunol. Methods 89 (1986) 239.

20 G. Sauerbrey: Z. Phys. 155 (1959) 206.

21 N. Kim, S.-H. Son and W.-Y. Kim: Sens. Actuators, B 198 (2014) 157.

22 V. Adam, J. Baloun, I. Fabrik, L. Trnkova and R. Kizek: Sensors 8 (2008) 2293.

23 N. Kim, S.-H. Son, C.-T. Kim, Y.-J. Cho, C.-J. Kim and W. Y. Kim: Sens. Actuators, B 157 (2011) 627.

24 S. Miyairi, S. Shibata and A. Naganuma: Anal. Biochem. 258 (1998) 168.

25 D. Kuhlmeier, E. Rodda, L. O. Kolarik, D. N. Furlong and R. Bilitewski: Biosens. Bioelectron. 18 (2003) 925. 